\title{
INVESTIGATION OF PVITHERMAL COLLECTOR MODELS FOR USE WITH GROUND SOURCE HEAT PUMPS IN TRANSIENT SIMULATIONS
}

\author{
Michele Pressani ${ }^{1}$, Nelson Sommerfeldt ${ }^{2}$ and Hatef Madani $^{2}$ \\ ${ }^{1}$ Politecnico di Milano, Milan, Italy \\ 2 KTH Royal Institute of Technology, Stockholm, Sweden
}

\begin{abstract}
Photovoltaic-thermal (PVT) collectors are commonly designed for use in domestic hot water systems, however it can be interesting to incorporate them into ground source heat pump (GSHP) systems. Because of the historically narrow use case, many PVT models are created with a collection of assumptions which may not apply to novel collectors designed for use in PVT + GSHP systems. The aims of this study are to review existing PVT collector models for use in TRNSYS, identify any potential error sources, and test for possible improvements. Type 560 is found to be the most promising theoretical model, however two potentially limiting features are identified; the radiation absorption model and the confinement to sheet-and-tube configurations. The absorption is tested using a recreation of Type 560 in Matlab where two alternative models developed specifically for PV modules are compared. The results show a marked increase in power during low angle, low light hours, and a $14.36 \%$ increase in electrical energy and a $10.91 \%$ for the thermal energy over the course of a day with one of the models. Collector geometry is tested by creating a 1D model in EES and comparing it to several geometries in Type 560. A method of packing as many tubes as possible together is shown to give comparable results as the $1 \mathrm{D}$ model. The results of these simulations will be compared with empirical data from currently ongoing testing.
\end{abstract}

Keywords: Solar PV/thermal, Transient Simulation, State-of-Art Review, Collector Geometry

\section{Introduction}

With the increasing interest in improving the energy efficiency of buildings, solar assisted heat pumps (SAHP) have been gaining attention. There are numerous potential configurations, but one of particular interest to heating dominated climates combine photovoltaic-thermal (PVT) hybrid solar collectors with ground source heat pumps (GSHP). Series configurations, where the solar collector is integrated on the source side of the heat pump, have been identified as a promising systems solution for PVT (Hardorn, 2015).

In this case, working fluid temperatures may often be lower than the ambient air which can lead to some nonconventional operating cases. For example, the collector can also be used as an air-to-water heat exchanger, capturing heat from the air in sensible and latent forms. The lower temperatures can also lead to lower PV cell temperatures, which may result in higher electricity production. Being on the source side may also limit the acceptable temperatures to be delivered to the evaporator, meaning higher flow rates during times of high irradiance may be necessary to avoid overheating.

Since these operating conditions are significantly different from PVT used for domestic hot water or direct space heating, it stands to reason that typical PVT designs may need to be modified for use with a GSHP. For example; larger or alternative flow channels from fin-and-tube, enhanced heat exchange on the rear of the panel rather than insulation, or accommodations for condensation.

Because of the interactions between components, it is critical to use a comprehensive modeling tool when designing hydraulic configurations and testing control strategies for a PVT+GSHP system. TRNSYS is a widely used and accepted, transient simulation tool for solar energy systems with many additional models for additional building components (Klein et al., 2009). Several solar thermal, PV, and PVT models have been 
incorporated, however they were developed with more traditional usage cases in mind and may not be as appropriate for PVT+GSHP applications. Therefore, the objective of this study is to develop a state-of-the-art PVT collector model for use in TRNSYS which can be incorporated into GSHP systems.

To meet this objective, a comprehensive review of existing PVT models is made with a focus on those which have already been implemented in TRNSYS. The study is limited to theoretical models rather than experimental since it is the general modeling of PVT that is of interest, rather than a particular module. Any critical limitations that are identified are tested by building new models or co-simulating with modifications to existing types in Matlab and EES, or using a combination of TRNSYS Types to overcome limitations to standalone models. The impact of the modifications will be tested against the existing TYPEs. Steady-state as well as quasi-steady state simulations are performed. The nomenclature used throughout is given in Tab. 1.

Tab. 1. List of nomenclature

\begin{tabular}{|c|c|c|}
\hline Quantity & Symbol & Unit \\
\hline Collector Area & $\mathrm{A}_{\mathrm{c}}$ & $m^{2}$ \\
\hline PV air mass coefficient & $a_{k}$ & - \\
\hline Air mass & $\mathrm{AM}$ & - \\
\hline Incidence angle modifier coefficient & $b_{o}$ & - \\
\hline Bond conductance & $\mathrm{C}_{\mathrm{b}}$ & $W m^{-1} K^{-1}$ \\
\hline Specific heat at constant pressure & $c_{p}$ & $J k g^{-1} K^{-1}$ \\
\hline External diameter of the tubes & $\mathrm{D}$ & $m$ \\
\hline Hydraulic diameter & $\mathrm{D}_{\mathrm{h}}$ & $m$ \\
\hline Collector efficiency factor & $\mathrm{F}^{\prime}$ & - \\
\hline Collector heat removal factor & $\mathrm{F}_{\mathrm{R}}$ & - \\
\hline Total radiation on horizontal surface & $\mathrm{G}$ & $W m^{-2}$ \\
\hline Beam radiation on horizontal surface & $\mathrm{G}_{\mathrm{b}}$ & $W m^{-2}$ \\
\hline Beam radiation on tilted surface & $\mathrm{G}_{\mathrm{b}, \mathrm{T}}$ & $W m^{-2}$ \\
\hline Diffuse radiation on horizontal surface & $\mathrm{G}_{\mathrm{d}}$ & $W m^{-2}$ \\
\hline Total radiation on tilted surface & $\mathrm{G}_{\mathrm{T}}$ & $W m^{-2}$ \\
\hline Convective heat transfer coefficient on the top of the PVT collector & $\mathrm{h}_{\text {conv-top }}$ & $W m^{-2} K^{-1}$ \\
\hline Convective heat transfer coefficient on the back of the PVT collector & $\mathrm{h}_{\text {conv-back }}$ & $W m^{-2} K^{-1}$ \\
\hline Heat transfer coefficient between the fluid and the tube wall & $\mathrm{h}_{\mathrm{fl}}$ & $W m^{-2} K^{-1}$ \\
\hline Radiative heat transfer coefficient & $\mathrm{h}_{\mathrm{rad}}$ & $W m^{-2} K^{-1}$ \\
\hline Length of a collector & $\mathrm{L}_{1}$ & $\mathrm{~m}$ \\
\hline Width of a collector & $\mathrm{L}_{2}$ & $\mathrm{~m}$ \\
\hline Thickness of the rectangular water layer & $\mathrm{L}_{3}$ & $\mathrm{~m}$ \\
\hline Air mass modifier & M & - \\
\hline Mass flow rate & $\dot{\mathrm{m}}$ & $k g s^{-1}$ \\
\hline Number of tubes & $\mathrm{N}_{\text {tubes }}$ & - \\
\hline Electrical power gain & $\mathrm{Q}_{\mathrm{el}}$ & $\mathrm{W}$ \\
\hline Thermal power gain & $\mathrm{Q}_{\mathrm{th}}$ & W \\
\hline Conductivity thermal resistance & $\mathrm{R}$ & $m^{2} K W^{-1}$ \\
\hline Solar absorbed radiation & $\mathrm{S}_{\mathrm{abs}}$ & $W m^{-2}$ \\
\hline Temperature & $\mathrm{T}$ & $\mathrm{K}$ \\
\hline Ambient temperature & $\mathrm{T}_{\mathrm{a}}$ & $\mathrm{K}$ \\
\hline Temperature around the tube & $\mathrm{T}_{\mathrm{b}}$ & $\mathrm{K}$ \\
\hline Mean fluid temperature & $\overline{\mathrm{T}_{\mathrm{fl}}}$ & $\mathrm{K}$ \\
\hline Inlet fluid temperature & $\mathrm{T}_{\mathrm{fi}}$ & $\mathrm{K}$ \\
\hline Outlet fluid temperature & $\mathrm{T}_{\mathrm{fo}}$ & $\mathrm{K}$ \\
\hline Sky temperature & $\mathrm{T}_{\text {sky }}$ & $\mathrm{K}$ \\
\hline Overall thermal loss coefficient & $\mathrm{U}_{\mathrm{L}}$ & $W m^{-2} K^{-1}$ \\
\hline Top loss coefficient & $\mathrm{U}_{\mathrm{t}}$ & $W m^{-2} K^{-1}$ \\
\hline Wind velocity & $\mathrm{V}_{\text {wind }}$ & $m s^{-1}$ \\
\hline
\end{tabular}




\begin{tabular}{lcc}
\hline Greek & Symbol & Unit \\
\hline Absorptance & $\alpha$ & - \\
Slope of the collector & $\beta_{\mathrm{a}}$ & $K^{-1}$ \\
Type 50 temperature coefficient & $\mathrm{K}_{\tau \alpha}$ & - \\
Incidence angle modifier & $\varepsilon$ & - \\
Emissivity & $\eta_{\mathrm{PV}}$ & - \\
Electrical efficiency & $\eta_{\mathrm{th}}$ & - \\
Thermal efficiency & $\eta_{\mathrm{a}}$ & - \\
PV module efficiency (-) when $\mathrm{T}_{\mathrm{PV}}=\mathrm{T}_{\mathrm{a}}$ & $\sigma$ & $W^{-2} K^{-4}$ \\
Stefan-Boltzmann constant & $\tau$ & - \\
Transmittance & $\xi$ & - \\
Packing factor & $\ddots$ & - \\
Angle of incidence & $\theta_{\mathrm{z}}$ & $\circ$ \\
Zenith angle & $\rho_{\mathrm{g}}$ & - \\
Ground reflectance & $\gamma$ & $K^{-1}$ \\
PV module temperature coefficient & & \\
\hline & $\mathrm{Symbol}$ & Unit \\
\hline Subscripts and abbreviations & $b$ & - \\
\hline Beam & $B I P V T$ & - \\
Building Integrated Photovoltaic-Thermal & $d$ & - \\
Diffuse & $E V A$ & - \\
Ethylene Vinyl Acetate & $g$ & - \\
Ground reflected & $G S H P$ & - \\
Ground Source Heat Pump & $i$ & - \\
Radiation component & $I A M$ & - \\
Incidence angle modifier & $n$ & - \\
Normal & $P V$ & - \\
Photovoltaic Panel & $P V T$ & - \\
Photovoltaic-Thermal & $r e f$ & - \\
Standard Test Condition & $S A H P$ & - \\
Solar Assisted Heat Pump & $*$ & - \\
Modified & & \\
\hline & & - \\
\hline
\end{tabular}

\section{Review}

PVT modeling in TRNSYS is by-in-large based on solar thermal collectors with the PV layer added to the front. This section reviews these models in detail as they have been applied to PVT models, as well as modifications made by succeeding authors.

\subsection{Type 50}

Type 50 is a modification of the Hottel-Whillier (1955) model used in Type 1 and is presented by Florscheutz (1979). It is available in the default TRNSYS library, can be used with glazed and unglazed modules, and is the most widely used PVT Type (Pressiani, 2016). The model is built on the assumption that the PV cells are laminated directly to the absorber plate, and thus the cells and the absorber are considered to have the same temperature.

The electrical power output $Q_{e l}$ is calculated with eq. 1 .

$Q_{e l}=A_{c} \tau \mathrm{G}_{\mathrm{T}} \eta_{a}\left\{1-\beta_{\mathrm{a}}\left[F_{R}\left(T_{f i}-T_{a}\right)+\frac{S_{a b s}}{U_{L}}\left(1-F_{R}\right)\right]\right\}$

Eq. 2 defines the useful thermal output $Q_{t h}$ of the combined collector. 
$\mathrm{Q}_{t h}=F_{R} A_{C}\left[S_{a b s}-U_{L}\left(T_{f i}-T_{a}\right)\right]$

Where $F_{R}$ is the collector heat removal factor shown in eq. 3.

$F_{R}=\frac{\dot{m} c_{p}}{A_{c} U_{L}}\left[1-\exp \left(-\frac{U_{L} F^{\prime} A_{c}}{\dot{m} c_{p}}\right)\right]$

The absorbed radiation $S_{a b s}$ is calculated using eq. 4 .

$S_{a b s}=\mathrm{G}_{\mathrm{T}}\left(1-\frac{\eta_{a}}{\alpha}\right)(\tau \alpha)$

There are eight different operational modes: modes 1 to 4 simulate flat-plate collectors with an increasing level of complexity in the heat loss calculations, modes 5 to 8 are used to model concentrating solar collectors, which is outside the scope of this study. In mode one the heat loss coefficient $\left(U_{L}\right)$ and the angular dependence of $(\tau \alpha)$ are set as constant values. This mode is recommended for all cases except those for which the assumption may introduce significant error in the calculated performance. Mode two calculates $U_{L}$ as a function of the operating temperatures, the wind speed and the collector geometry using Klein's equation (1975). In mode three $U_{L}$ is set as a constant and $\tau$ is considered using Hottel-Woertz (1944). Mode four is a combination of modes two and three, however it can only be used with glazed collectors.

Shortcomings of Type 50 have been noted by several authors over the years. A significant source of error is the lumped temperature of the absorber and the PV cells, which when measured was found to be up to $12 \mathrm{~K}$ different and result in electric overproduction of $10 \%$ (Raghuraman, 1981). Later simulations would demonstrate that the temperature gradients between cooling tubes are much higher when a thermal resistance is added between the layers, also identifying a greater average temperature difference (Mazara, 2009). The collector efficiency factor $\left(F^{\prime}\right)$ in eq. 3 is an input in Type 50 and constant throughout the simulation, even though it is a function of irradiation, wind speed, and internal temperature of the collector layers. This assumption may be appropriate for glazed collectors, but will likely lead to greater errors in unglazed PVTs (Bilbao and Sproul, 2012). An issue directly related to the PVT+GSHP concept is the calculation of the top loss coefficient $\left(U_{t}\right)$, which uses the mean absorber temperature rather than the fluid temperature, potentially causing increased errors when the fluid temperature is lower than ambient (Bilbao and Sproul, 2012). Type 50 doesn't consider the thermal resistance of the bond between absorber and the tube $\left(\mathrm{C}_{\mathrm{b}}=\infty\right)$.

The algorithm used in Type 50 may also be a source of error. The Florscheutz model requires multiple iterations to converge on a solution. Type 50 is hard coded to perform only three iterations, which may not be enough to reach an acceptable convergence (Bilbao and Sproul, 2012). Additionally, a floating point error can cause the simulation to fail (Collins, 2009).

\subsection{Type 560}

Type 560 has been created as a dedicated unglazed PVT model using heat transfer equations derived by DuffieBeckman (1991) based on energy balances of the PV layer, absorber fins, and absorber tubes. Like Type 50, it uses an iterative approach to solve the analytical equations until convergence is reached and is also based on a fin-tube absorber design.

The electrical power output $Q_{e l}$ is defined with eq. 5 .

$Q_{e l}=(\tau \alpha)_{n}(I A M) G_{T} \eta_{P V} A_{c}$

The thermal power output $Q_{t h}$ is calculated with eq. 6 .

$Q_{t h}=\dot{m} c_{p}\left(T_{f o}-T_{f i}\right)$

The outlet fluid temperature $T_{f o}$ can be written using eq. 7 .

$T_{f o}=\left(T_{f i}+\frac{C_{1}}{C_{2}}\right) \exp \left(\frac{N_{\text {tubes }} C_{2} L}{\dot{m} c_{p} C_{3}}\right)-\frac{C_{1}}{C_{2}}$

The coefficients $C_{1}, C_{2}$, and $C_{3}$ are based on the fin-tube geometry and material properties, as well as the heat transfer coefficients with the surroundings.

A notable feature of Type 560 is that it considers the PV and absorber layers separately, allowing the user to 
define the thermal resistance between them. It also considers convection coefficients as inputs. In Type 50, wind speed is an input and the convection coefficient on the front of the collector is calculated using the linear relationship defined by McAdams (1954). This allows users to calculate convection externally using Type 1232 or a custom equation. Convective and radiative heat transfer is also considered on the back side of the module in Type 560, which is of particular interest in a PVT without insulation.

\subsection{Modifications to Type 50 and 560}

Upon the identification of limitations to Type 50, a small library of modified Types were created as a part of the IEA Solar Heating and Cooling Task 35 and are freely available for download (Collins, 2009). Type 250 is the flat plate, water cooled model in the library and is a modification of Type 50d. Modifications to the model include the correction of the floating point error which lead to a division by zero and the correction of an error in the PV efficiency equation related to the temperature coefficient.

Several authors have created their own versions of Type 50 by connecting their own PV electrical equations with Type 1. For calculating PV output, Elswijk et al. (2004) used a linear temperature relationship similar to Types 50 and 560 and used the mean fluid temperature from Type 1 to determine cell temperature. Kalogirou and Tripanagnostopoulos (2006) use the same linear relationship to temperature, however they use a combination of standalone PV module temperature models with the PVT fluid temperature to determine cell temperature.

Type 563 is an alternative version to 560 which relies on the same thermodynamic model but is intended for building integrated PVT. The modification connects the back side temperature to the interior air node in a multi-zone building model. This allows the building model to take into consideration the heat transfer of the PVT modules on the building energy balance.

\subsection{Other PVT Types}

A number of researchers have created custom PVT models in recent decades using a variety of approaches. Some of these have been adapted for use in TRNSYS. Kalogirou (2001) created Type 49 based on the work of Bergene and Lovvik (1995). Their approach is similar to Duffie-Beckman but use a 2D steady state model which considers temperature gradients in the surface plane of the module. Like Type 50, temperature gradients through the thickness of the PV and absorber are not considered. Fraisse et al. (2007) used an electrical current analogy applied to heat transfer to create Type 105. The model is capable of glazed and unglazed PVT collectors and is described by 12 nodes with heat capacities that handle the dynamic behavior of each layer. Bilbao and Sproul (2012) developed Type 850 which is mathematically similar to Type 50 in that it assumes the PV cell temperature is the same as the absorber, however it uses a numerical solving approach and a top heat loss coefficient model by Akhtar and Mullick (1999). Dupeyrat et al. (2014) use Type 832, a thermal collector model original developed by Perers and Bales (2002) and extended most recently by Haller et al. (2012) which relies on experimental data to determine its coefficients. They modify it to include the electrical portion using an experimentally derived relationship between temperature and PV power.

\subsection{Review conclusions}

There have been numerous studies towards the goal of modeling PVT collectors, many of which are directed towards use in TRNSYS due to its ability to model complete solar energy systems. The vast majority of work has been based on the original solar thermal model by Hottel-Whillier and integrated into Type 50. As noted above, Type 50 has a number of computational shortcomings as well as physical limitations. Two significant issues are the matching PV cell temperature with the absorber layer and the limited modeling capabilities of heat transfer with the surroundings. In PVT collectors where the PV cells are laminated directly to the absorber with very high conductivity, then the single temperature assumption is more reasonable. However, this limits the type of collectors which can be explored. Similarly, the heat transfer with the surroundings is unique with PVT+GSHP systems given the potential for collector temperatures well below ambient. These issues limit the applicability of Type 50 and its derivatives to PVT+GSHP system models.

Type 560 offers a multi-layered model which solves the major shortcomings of Type 50. Surprisingly, it is not used by nearly as many researchers as Type 50 , and there is little documentation to validate its performance with experimental data. However, the theoretical foundations make it a more promising tool for use with novel PVT collector designs in GSHP system simulations.

Nevertheless, Type 560 does have artifacts which may be a source of error for unglazed and uninsulated PVT 
collectors. There are several which have been identified (Pressiani, 2016), only two are discussed here. First, the model used for absorbed radiation is derived from a glazed thermal collector, rather than an unglazed PV module. Second, the model is entirely based on the traditional fin-tube design, which may not be representative of other configurations, such as roll bond construction, that could have other flow patterns.

\section{Models and Results}

In consideration of the artifacts listed above regarding Type 560, alternative models are tested to see if there are any impacts on electric and/or thermal production. The alternative models are only tested against the default 560 model. To make the modifications, the Fortran code from Type 560 has been recreated in Matlab and EES.

\subsection{Absorbed radiation}

Testing the absorbed radiation is performed with transient simulations over the course of one day, using TMY2 weather data for Stockholm-Arlanda from June $1^{\text {st }}$, and a time step of 10 minutes. The model used to calculate the total amount of incident radiation absorbed by the PV surface in Type 560 is based on Liu and Jordan's (1963) isotropic sky method and represented by eq. 8 .

$S_{a b s}=(\tau \alpha)_{n}(I A M) G_{T}=(\tau \alpha)_{n}\left(G_{b, T} K_{\tau \alpha, b}+G_{d} K_{\tau \alpha, d} \frac{1+\cos \beta}{2}+G \rho_{g} K_{\tau \alpha, g} \frac{1-\cos \beta}{2}\right)$

Where $K_{\tau \alpha, i}$ is represented by eq. 9 .

$K_{\tau \alpha, i}=1-b_{0}\left(\frac{1}{\cos \theta_{i}}-1\right)$

And $G_{b, T}$ with eq. 10 .

$G_{b, T}=G_{T}-G_{d} \frac{1+\cos \beta}{2}-G \rho_{g} \frac{1-\cos \beta}{2}$

While developing an improved PV generation model, De Soto (2004) proposes a PV specific absorption term described in eq. 11 .

$S_{a b s}=(\tau \alpha)_{n} M(I A M) G_{T}=(\tau \alpha)_{n} M\left(G_{b, T} k_{\tau \alpha, b}+G_{d} k_{\tau \alpha, d} \frac{1+\cos \beta}{2}+G \rho_{g} k_{\tau \alpha, g} \frac{1-\cos \beta}{2}\right)$

Where $K_{\tau \alpha, i}$ is represented by eq. 12. that defines light refraction passing through a single pane of glass without an air gap on the other side. This better represents a standard PV module, similar to what would be found in an unglazed PVT.

$K_{\tau \alpha, i}=\frac{\left(\tau \alpha\left(\theta_{i}\right)\right)_{i}}{(\tau \alpha)_{n}}$

$G_{b, T}$ is also modified and shown in eq. 13.

$G_{b, T}=G_{b} R_{b}=\frac{\cos \theta_{b}}{\cos \theta_{z}}\left(G-G_{d}\right)$

A new term, $M$, represents the air mass modifier to account for changes in spectral distribution due to air mass, and is described with eq. 14 (King et al., 2004). The coefficients $a_{k}$ are constants based the cell material (De Soto et al., 2006).

$M=\sum_{k=0}^{4} a_{k}(A M)^{k}$

For zenith angles between $0^{\circ}$ and $60^{\circ}$, the air mass is represented with eq. 15 , and for angles beyond $60^{\circ}$ is described by Kasten and Young (1989). 
$A M=\frac{1}{\cos \left(\theta_{z}\right)}$

In most absorption models, the PV cell is the only material considered even though there are gaps and busbars which are also present. Santbergen and van Zolingen (2008) consider the absorptivity of the multiple surfaces of a PV module using a dedicated optical model. The absorptivity model is represented by eq. 16 .

$\alpha=\tau\left(\xi \alpha_{\text {cell }}+(1-\xi) \alpha_{\text {space between cells }}\right)$

$G_{b, T}$ is calculated using eq. 10 and the effective absorptivity with eq. 17 . The packing density $\xi$ is the ratio of the module area that are active PV cells to the total area of the module.

$S_{a b s}=\alpha\left(G_{b, T}+G_{d} \frac{1+\cos \beta}{2}+G \rho_{g} \frac{1-\cos \beta}{2}\right)$

The three radiation absorption models (Type 560, De Soto, Santbergen) are tested using identical conditions and input values where possible. In cases where model specific terms are considered, values representing a typical mono-crystalline PV module are used.

The results in Fig. 1 show that Type 560 has the lowest electrical power output. Relative to 560, the De Soto model is higher across the entire day, while Santbergen has notably higher output during the morning and evening hours when there are low incident angles. The peak difference occurs in both models during the morning, with De Soto being 38.1\% greater and Santbergen 44.5\%. During the midday when there is much greater production, the De Soto model is about $13 \%$ greater. In terms of electrical energy generation, Type 560 produced $1.692 \mathrm{kWh}$, De Soto $1.798 \mathrm{kWh}$, and Santbergen $1.975 \mathrm{kWh}$ for the day, suggesting that over a year there could be significant differences in this portion of the model.
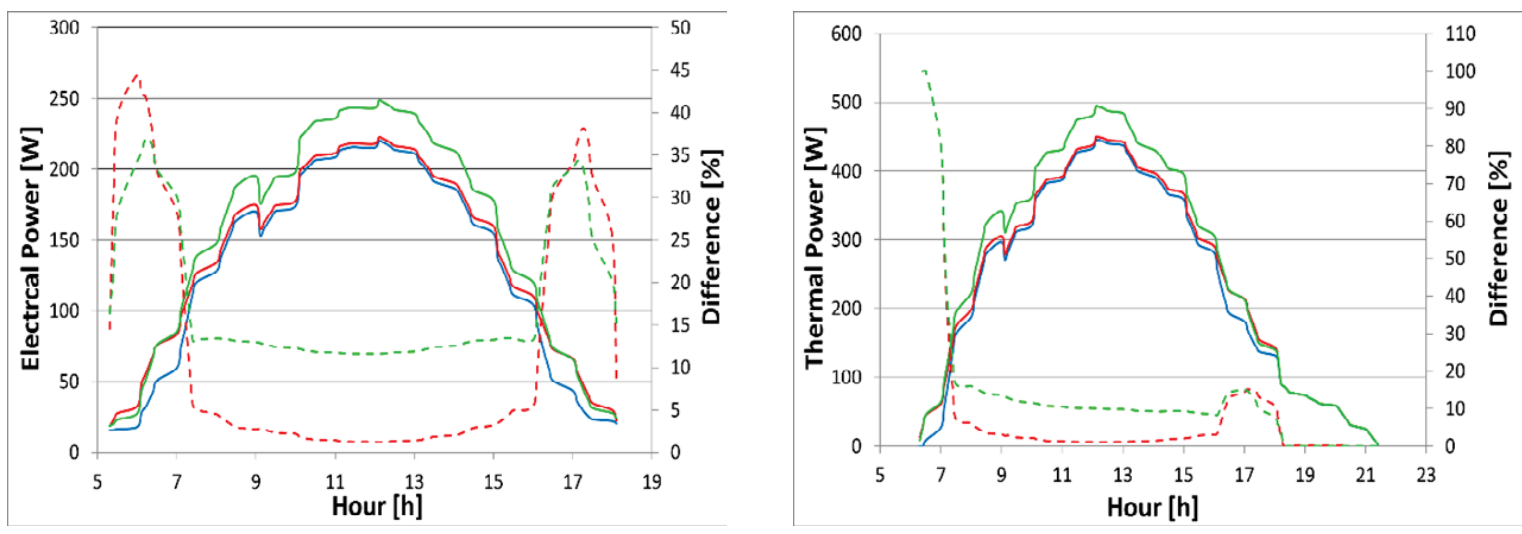

—TYPE 560 —Santbergen —De Soto - -Difference TYPE 560-Santbergen - -Difference TYPE 560-De Soto

Fig. 1. Electrical and thermal output comparison of Type 560, De Soto, and Santbergen radiation absorption models

The thermal output results show once again that De Soto is shown to have significantly higher output throughout most of the day. The differences in the early and late hours are less pronounces as in the electrical generation, particularly in the later hours where all three models match exactly. During the midday, De Soto gives a $10-18 \%$ higher output while Santbergen is usually under 5\% greater. Total thermal production for the day from each model is $3.575 \mathrm{kWh}$ for Type 560, $3.713 \mathrm{kWh}$ for De Soto, and 4.012 kWh for Santbergen.

\subsection{Alternative Collector Geometry}

One of the main limitations of Type 560 is that the only absorber design is a sheet and tube, represented by Fig. 2a. If another geometry is considered, like the rectangular channel absorber in Fig. 2b, then it is possible to use the hydraulic diameter. In Type 560 there's the assumption that the temperature $\left(T_{b}\right)$ around the tube is uniform. This may not be true for all types of design, for example with a single channel like in Fig. $2 \mathrm{c}$ where there is direct contact on one side and no insulation on the rear, $T_{b, 1}$ could have a significantly different value from $T_{b, 2}$. 

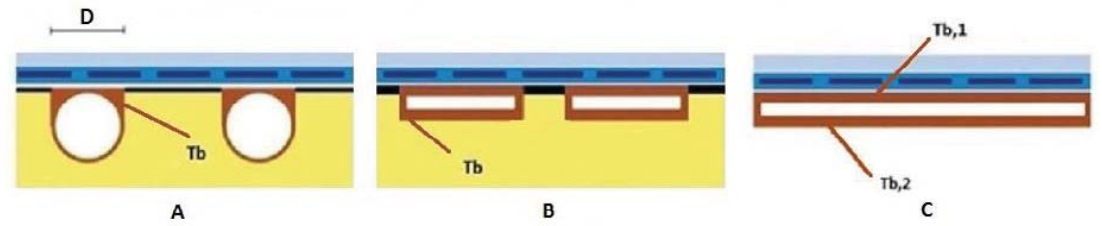

Fig. 2. Different absorber geometry

A 1D steady state model is built with EES in order to simulate the geometry with one single rectangular channel (Fig. 2c). The single channel configuration is used as a way to examine designs which do not have large gaps between the parallel tubes. The proposed model is then compared with several configurations of Type 560 which attempt to mimic the single channel design. A cross section of the layered construction which the 1D model is based on is shown in Fig. 3, and is based on a prototype collector currently in development. The model is built using energy balances over multiple layers within the collector; the top glass, PV, bottom glass, and the metal back layer.

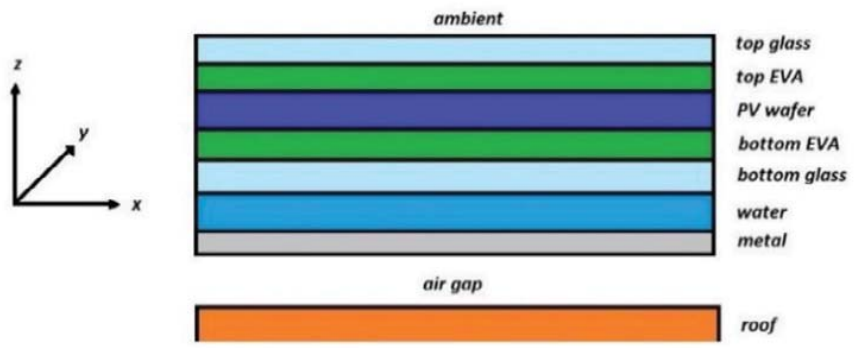

Fig. 3. PV/T collector representation

The energy balance on the top glass cover is given by eq. 18 .

$\frac{T_{P V}-T_{\text {top-glass }}}{R_{\text {top-glass }}+R_{\text {top-eva }}+R_{P V}}-h_{\text {rad }}\left(T_{\text {top-glass }}-T_{\text {sky }}\right)-h_{\text {conv-top }}\left(T_{\text {top-glass }}-T_{a}\right)=0$

Where $h_{\text {rad }}$ is represented with eq. 19:

$h_{\text {rad }}=\varepsilon_{g} \sigma\left(T_{\text {top-glass }}+T_{\text {sky }}\right)\left(T_{\text {top-glass }}^{2}+T_{\text {sky }}^{2}\right)$

Eq. 20 gives the energy balance on the PV cells.

$S_{\text {abs }}-\frac{T_{P V}-T_{\text {top-glass }}}{R_{\text {top-glass }}+R_{\text {top-eva }}+R_{P V}}-\frac{T_{P V}-T_{\text {bottom-glass }}}{R_{\text {bottom-eva }}+R_{\text {bottom-glass }}}-\frac{Q_{e l}}{A_{c}}=0$

Where $Q_{e l}$ is represented with eq. 21. $S_{a b s}$ is described with eq.8.

$Q_{e l}=G_{T} \eta_{\mathrm{PV}, \mathrm{ref}}\left[1-\gamma\left(\mathrm{T}_{\mathrm{PV}}-\mathrm{T}_{\mathrm{PV}, \mathrm{ref}}\right)\right] A_{c}$

The energy balance on the bottom glass is given by eq. 22 .

$\frac{T_{P V}-T_{\text {bottom-glass }}}{R_{\text {bottom-eva }}+R_{\text {bottom-glass }}}-h_{f l}\left(T_{\text {bottom-glass }}-\overline{T_{f l}}\right)=0$

Eq. 23 and 24 represent the energy balance on the metallic backing on the fluid channel.

$\frac{\left(T_{\text {back }}-T_{\text {metal }}\right)}{R_{\text {metal }}}-h_{f l}\left(T_{\text {metal }}-\overline{T_{f l}}\right)=0$
$h_{\text {conv-back }}\left(T_{a m b}-T_{\text {back }}\right)-\frac{\left(T_{\text {back }}-T_{\text {metal }}\right)}{R_{\text {metal }}}=0$

The convective heat transfer coefficients $h_{\text {conv-top }}$ and $h_{\text {conv-back }}$ follows Cole and Sturrock's formula (1977). 
The average working fluid temperature in the collector $\overline{T_{f l}}$ is calculated with eq. 25 .

$\overline{T_{f l}}=\frac{\frac{T_{\text {bottom-glass }}+T_{\text {metal }}}{2}-T_{f i}}{\frac{2 h_{f l} L_{1} L_{2}}{\dot{m} c p}}\left(\exp \left(-\frac{2 h_{f l} L_{1} L_{2}}{\dot{m} c p}\right)-1\right)+\frac{T_{\text {bottom-glass }}+T_{\text {metal }}}{2}$

The convective heat transfer coefficient $h_{f l}$ is calculated for laminar and turbulent flow using Nusselt correlations.

The final output for thermal power $Q_{t h}$ is given by eq. 26 .

$Q_{t h}=\dot{m} c p\left(T_{f o}-T_{f i}\right)$

Where the outlet temperature $T_{f o}$ is given by eq. 27 :

$T_{f o}=\left(T_{f i}-\frac{T_{\text {bottom-glass }}+T_{\text {metal }}}{2}\right) \exp \left(-\frac{2 h_{f l} L_{1} L_{2}}{\dot{m} c p}\right)+\frac{T_{\text {bottom-glass }}+T_{\text {metal }}}{2}$

There are three configurations of Type 560 tested; a single tube approach (I), a packed tube approach (II), and a typical collector design (III). The single channel approach considers one tube with a diameter equal to the width of the module, which is similar to the adaptation that can be made for designs like Fig. 2b. The packed channel approach places the tubes directly next to each other across the entire width, effectively removing the fins, which is represented in Fig. 4. The typical collector uses 10 tubes with diameters of $0.015 \mathrm{~m}$ in parallel, which result in absorber fins between them much like Fig. 2a, and is included as a control.

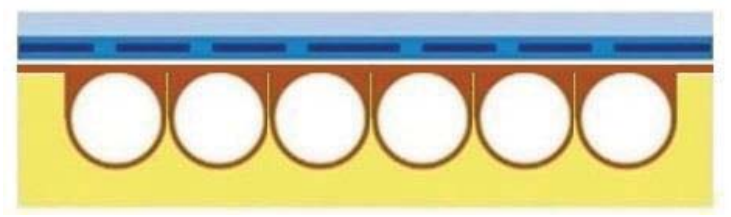

Fig. 4. Approximation of a rectangular water channel using the packed tube approach

To represent the single fluid channel directly in contact with the rear glass, the bond conductance between the tubes and absorber plate in all of the Type 560 models is set very high $\left(10^{10}\right)$ and the thickness very low $\left(10^{-10}\right)$. The resistance of the back glass in the $1 \mathrm{D}$ model is then incorporated into the absorber plate conductivity setting. The front and back convection coefficients in Type 560 are set to match the values used in the proposed 1D model. This means adding resistance to the front since Type 560 does not consider the glass and EVA layers on top of the PV. The convection coefficient inside the tubes are set using eq. 28 and 29.

$h_{f l}=\frac{h_{f l}^{*} D_{h}}{D}$

$h_{f l}^{*}=f\left(N u\left(D_{h}\right)\right)$

The four geometries are run using steady state simulations across a range of operating conditions. A range of inputs are considered for three external variables; wind velocity, ambient temperature, and mass flow rate. The default value for the wind is $1 \mathrm{~m} / \mathrm{s}$, ambient temperature is $10^{\circ} \mathrm{C}$, and the flow rate is $0.05 \mathrm{~kg} / \mathrm{s}$.

The electrical and thermal production results are shown in Fig. 5, with electrical on the left and thermal on the right. In both cases the packed tube approach (II) is the closest to the $1 \mathrm{D}$ model. The difference in electric output is only $0.63 \%$ and in thermal output $3.77 \%$. The greatest difference is found in the traditional collector design, highlighting the differences between the design concepts. 

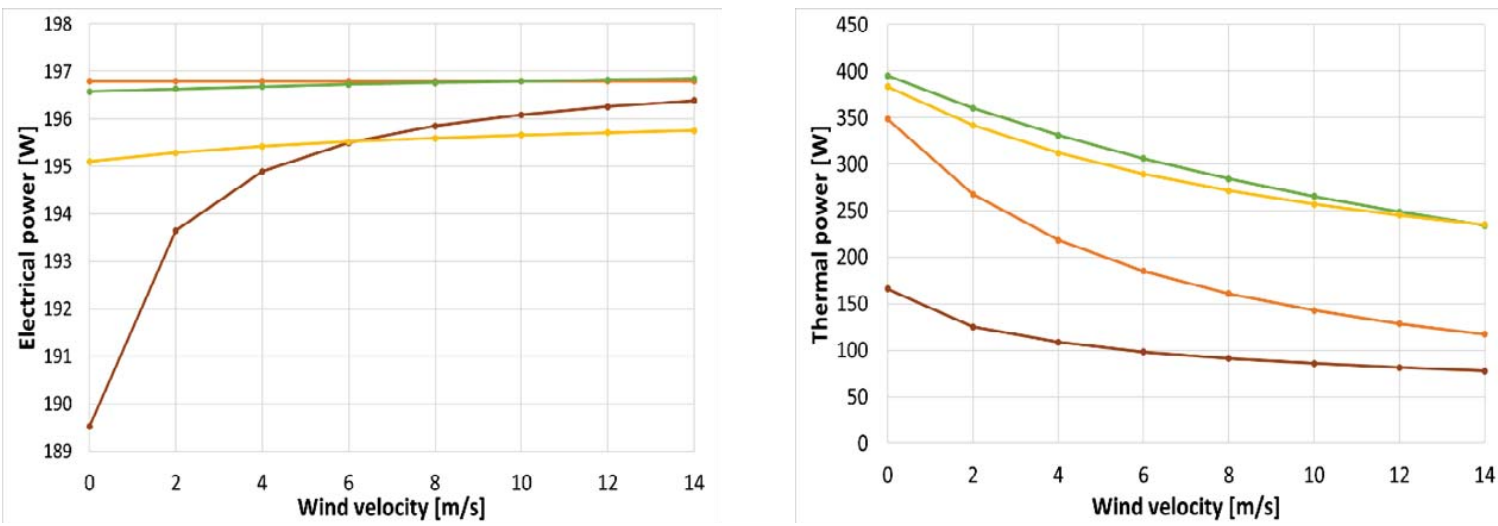

$\rightarrow$ Single tube $\rightarrow$ Packed tubes $\rightarrow$ Typical design $\rightarrow$ EES

Fig. 5. Electrical and thermal power outputs with wind velocity variation for multiple geometries

The relationship between power and ambient temperature are shown in Fig. 6. Once again the packed tube concept and 1D concept are best matched in both thermal and electrical output. The average difference is $1.20 \%$ for electrical and $8.36 \%$ in thermal. In this case the traditional collector had the greatest error again, but this time is significantly greater, with a variation of $59.92 \%$ for the thermal part.
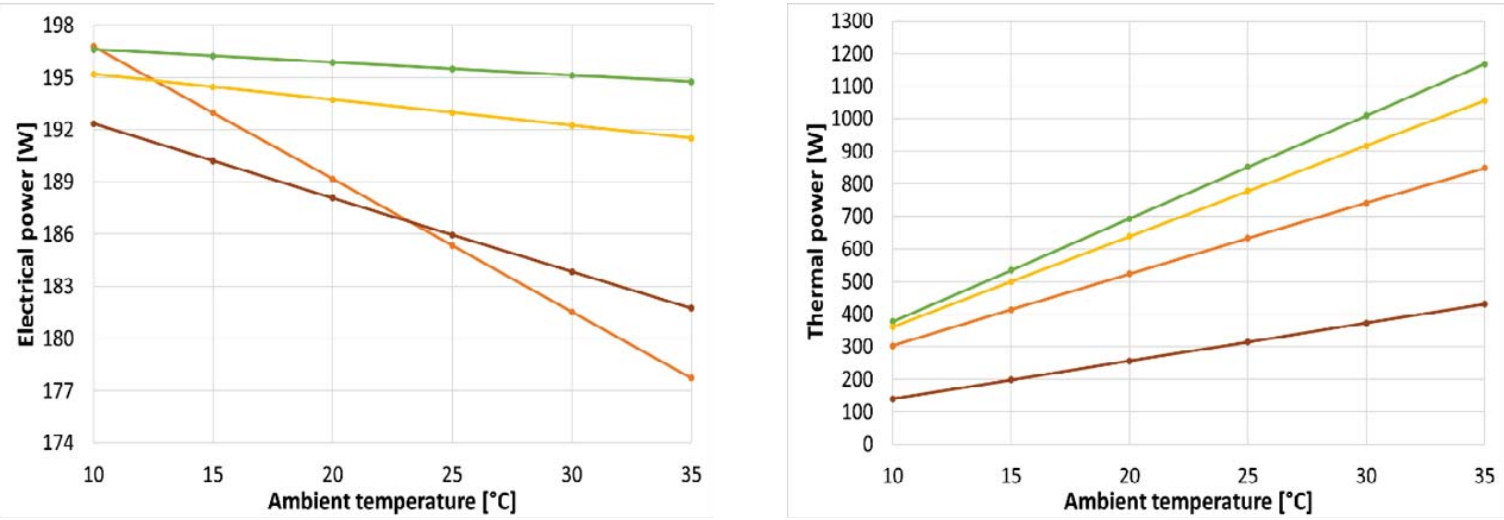

$\rightarrow$ Single tube $\rightarrow$ Packed tubes $\rightarrow$-Typical design $\rightarrow$ EES

Fig. 6. Electrical and thermal power outputs with ambient temperature variation for multiple geometries

$$
\rightarrow \text { Single tube } \rightarrow \text {-Packed tubes } \rightarrow \text { Typical design } \rightarrow \text { EES }
$$

Fig. 7 shows the trends in output related to mass flow rate.
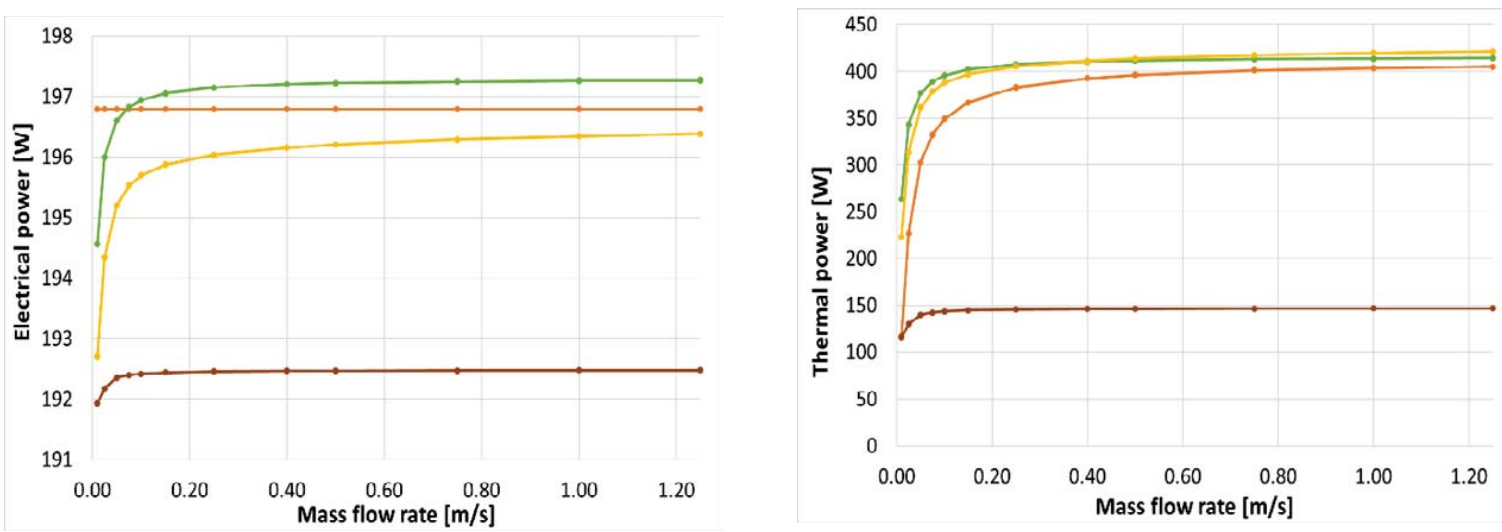

$$
\rightarrow \text { Single tube } \rightarrow \text {-Packed tubes } \rightarrow \text { Typical design } \rightarrow \text { EES }
$$

Fig. 7. Electrical and thermal power outputs with mass flow rate variation for multiple geometries 
The difference in electric production is small between each geometry, but again the packed tubed concept (II) matches the 1D model most closely. There's a difference of $0.62 \%$ for the electrical power output and $3.62 \%$ for the thermal one. A notable feature in these results is the deviation of the single tube concept (I) from the patterns of the others at low flow rates. This may be caused by an error in the way the convection coefficient is being calculated for the single tube. Once again in thermal output, the traditional collector geometry is significantly lower than the others, with a $62.07 \%$ of deviation.

\section{Discussion and Conclusions}

Upon review of the two most prominent TRNSYS models for PVT collectors, Type 50 and Type 560, the later model has been identified as the most promising representation for novel PVT designs. Type 850, which incorporated the thermal model Type 832 would also be a good choice, however it requires the construction and testing of a collector prior to use. Type 560 is a theoretical model and provides the most flexibility and control. Type 50 and its derivations are limiting by not considering resistance between the absorber and PV cells and the relatively basic convection interaction with the environment.

For exploring novel PVT collectors Type 560 is not without limitations, however, two of which have been explored here; radiation absorption and collector geometry. Two absorption models dedicated to PV modules demonstrated significant differences in electrical and thermal power output during low angle, low light conditions. One of the models, from De Soto (2004) showed increased power output during nearly all hours of the day. These differences require most testing given the limited results presented here. The impact on annual or lifetime production should be investigated. Validation with experimental data is also necessary.

The collector geometry limitation has been tested considering two possibly modifications with Type 560 and compared with a 1D model created in EES. The results showed that collector geometry has significant impact on output, and that is must be taken into consideration in the model. A method which places as many working fluid tubes together as possible gave the most similar results between Type 560 and the 1D model, and are close enough to recommend 560 for use in this collector design. This is beneficial since construction of a new Type can be a lengthy and difficult process.

A limitation to this work is that all of the results presented here are theoretical. Development and testing of a prototype PVT collector specifically for use with GSHP systems is currently being performed. Once completed, the results from this modeling can be compared to the empirical data to confirm and validate the models.

\section{Acknowledgement}

This research has been funded by Mistra Innovation (project no. MI15.18) for which the authors are grateful.

\section{References}

Akhtar, N., Mullick, S.C., 1999. Approximate method for computation of glass cover temperature and top heatloss coefficient of solar collectors with single glazing. Sol. Energy 66, 349-354. doi:10.1016/S0038092X(99)00032-8

Bergene, T., Løvvik, O.M., 1995. Model calculations on a flat-plate solar heat collector with integrated solar cells. Sol. energy 55, 453-462. doi:10.1016/0038-092X(95)00072-Y

Bilbao, J., Sproul, A., 2012. Analysis of flat plate photovoltaic-thermal (PVT) models. World Renew. Energy Forum 95-102.

Cole, R.J., Sturrock, N.S., 1977. The convective heat exchange at the external surface of buildings. Build. Environ. 12, 207-214. doi:10.1016/0360-1323(77)90021-X

Collins, M., 2009. A review of PV, solar thermal, and PV/thermal collector models in TRNSYS, IEA SHC Task 35 .

De Soto, W., 2004. Improvement and Validation of a Model for Photovoltaic Array Performance. University of Wisconsin-Madison.

De Soto, W., Klein, S. a., Beckman, W. a., 2006. Improvement and validation of a model for photovoltaic array performance. Sol. Energy 80, 78-88. doi:10.1016/j.solener.2005.06.010

Duffie, J.A., Beckman, W.A., 1991. Solar Engineering of Thermal Processes, Second. ed. John Wiley \& Sons, Inc., Hoboken, NJ. 
Dupeyrat, P., Ménézo, C., Fortuin, S., 2014. Study of the thermal and electrical performances of PVT solar hot water system. Energy Build. 68, 751-755. doi:10.1016/j.enbuild.2012.09.032

Elswijk, M.J., Jong, M.J.M., Strootman, K.J., Braakman, J.N.C., de Lange, E.T.N., Smit, W.F., 2004. Photovoltaic/thermal Collectors in Large Solar Thermal Systems, in: 19th European Photovoltaic Solar Energy Conference and Exhibition. Paris.

Florschuetz, L.W., 1979. Extension of the Hottel-Whillier model to the analysis of combined photovoltaic/thermal flat plate collectors. Sol. Energy 22, 361-366. doi:10.1016/0038-092X(79)90190-7

Fraisse, G., Ménézo, C., Johannes, K., 2007. Energy performance of water hybrid PV/T collectors applied to combisystems of Direct Solar Floor type. Sol. Energy 81, 1426-1438. doi:10.1016/j.solener.2006.11.017

Haller, M.Y., Perers, B., Bales, C., Paavilainen, J., Dalibard, A., Fischer, S., Bertram, E., 2012. TRNSYS Type 832 v5.00, Dynamic Collector Model by Bengt Perers: Updated Input-Output Reference.

Hardorn, J.-C. (Editor), 2015. Solar and Heat Pump Systems for Residential Buildings, First. ed. Ernst \& Sohn GmbH \& Co., Berlin.

Hottel, H.C., Whillier, A., 1955. Evaluation of flat-plate solar collector performance, in: Transcript of the Conference on the Use of Solar Energy, The Scientific Basis, Vol. II, Part 1, Section A. University of Arizona Press, Tucson, Arizona, pp. 74-104.

Hottel, H.C., Woertz, B.B., 1944. Performance of Flat-Plate Solar-Heat Collectors. ASME Trans. 64, 91.

Kalogirou, S.A., 2001. Use a TRNSYS for modelling and simulation of a hybrid pv-thermal solar system for Cyprus. Renew. Energy 23, 247-260. doi:10.1016/S0960-1481(00)00176-2

Kalogirou, S. a., Tripanagnostopoulos, Y., 2006. Hybrid PV/T solar systems for domestic hot water and electricity production. Energy Convers. Manag. 47, 3368-3382. doi:10.1016/j.enconman.2006.01.012

Kasten, F., Young, A.T., 1989. Revised optical air mass tables and approximation formula. Appl. Opt. 28, 4735-4738. doi:10.1364/AO.28.004735

King, D.L., Boyson, W.E., Kratochvill, J.A., 2004. Photovoltaic Array Performance Model. Sandia National Laboratories, SAND2004-3535.

Klein, S.A., 1975. Calculation of flat-plate collector loss coefficients. Sol. Energy 17, 79-80.

Klein, S., Beckman, W.A., Mitchell, J., Duffie, J.A., Freeman, T., 2009. TRNSYS 17, A Transient System Simulation Program.

Liu, B.Y.H., Jordan, R.C., 1963. A Rational Procedure for Predicting The Long-Term Average Performance of Flat-Plate Solar-Energy Collectors. Sol. Energy 7, 53-74. doi:10.1016/0038-092X(63)90006-9

Mazara, A., 2009. Analisi termica di collettori cogenerativi fotovoltaici-termici. Politecnico Milano.

McAdams, W.H., 1954. Heat Transmission, Third. ed. McGraw-Hill, New York.

Perers, B., Bales, C., 2002. A Solar Collector Model for TRNSYS Simulation and System Testing, IEA SHC Task 26.

Pressiani, M., 2016. Photovoltaic/thermal hybrid solar collectors: TRNSYS analysis and possible improvements. Politecnico Milano.

Raghuraman, P., 1981. Analytical Predictions of Liquid and Air Photovoltaic/Thermal, Flat-Plate Collector Performance. J. Sol. Energy Eng. 103, 291-298. doi:10.1115/1.3266256

Santbergen, R., van Zolingen, R.J.C., 2008. The absorption factor of crystalline silicon PV cells: A numerical and experimental study. Sol. Energy Mater. Sol. Cells 92, 432-444. doi:10.1016/j.solmat.2007.10.005 